\title{
Small for Gestational Age for Weight and Length
}

National Cancer Institute

\section{Source}

National Cancer Institute. Small for Gestational Age for Weight and Length. NCI

Thesaurus. Code C118700.

Birth weight and length greater than two standard deviations below the mean for the reference population of the same sex and gestational age. 